\title{
NANO-MAGNETODIELECTRIC COMPOSITE BASED SUBSTRATE FOR USE IN MICROWAVE PLANAR DEVICES IN X-BAND
}

\author{
Arunav Phukan ${ }^{1}$, Nidhi S Bhattacharyya ${ }^{2}$ \\ ${ }^{I}$ Microwave Engineering Laboratory, Department of Physics, Tezpur Central University, India \\ ${ }^{2}$ Microwave Engineering Laboratory, Department of Physics, Tezpur Central University, India
}

\begin{abstract}
Magnetodielectric materials provide a new dimension for developing miniaturized substrates for microwave applications. Miniaturization in microwave planar devices depends on both the real part of complex permittivity $\left(\varepsilon_{r}\right)$ and complex permeability $\left(\mu_{r}\right)$ of the substrate. Major shortfalls of using high $\varepsilon_{r}$ substrates are lowering of radiation efficiency, pattern degradation (due to excitation of surface waves) and lowering of impedance bandwidth. Miniaturization can also be achieved by modifying the other parameter $\mu_{r}$. Bulk ferrites, generally, have high saturation magnetization and dispersive magnetic losses and needs strong external dc-bias fields to alter its permeability property, making it unsuitable for compact applications. Nano sized ferrites are reported to have low saturation magnetizations and low eddy current losses. Composites made using nano ferrite inclusions in polymers can result in natural magnetodielectric materials with low magnetic losses. The current study aims to develop low loss flexible nano-magnetodielectric composite based substrates for use in microwave planar devices in X-band (8.2-12.4 GHz). $\mathrm{Co}_{0.65} \mathrm{Ni}_{0.35} \mathrm{Fe}_{2} \mathrm{O}_{4}$ embedded in $\mathrm{SiO}_{2}$ matrix is synthesized using a modified sol-gel method starting from tetraethylorthosilicate (TEOS) and metal $\left(\mathrm{Fe}^{I I I}, \mathrm{Co}^{I I}, \mathrm{Ni}^{I I}\right)$ nitrates and ethylene glycol. Two synthesis routes are chosen (one with $\mathrm{H}_{2} \mathrm{O}$ being added externally and one without) and the obtained powders are annealed at different temperatures $\left(500-1000{ }^{\circ} \mathrm{C}\right)$ and characterized using XRD. The powders are mixed in 1:1 ratio with silicone for obtaining a flexible structure. Microwave characterizations of the flexible substrates are then carried out to determine the losses in the X-band regime.
\end{abstract}

\section{INTRODUCTION}

Integration of more communication standards in one microwave wireless device has created demand on developing compact, low-cost, and robust multi-band microwave components. Considering the structure of the microwave planar circuits or devices, the substrate is one of its major elements and hence it has a substantial role in determining the devices' size as well as its performance. In real sense, the complex permittivity and complex permeability of the substrate material decides the geometry, size of the circuit and to a large extent its performance efficiency also. Hence, altering the complex permittivity and complex permeability of the substrate in use, provides us the scope to improve the efficiency and also to miniaturize the microwave devices.

Miniaturization in microwave devices, denoted by factor, $\mathrm{n}$, is given as $\mathrm{n}=\sqrt{\varepsilon_{r} \mu_{r}}$, where, $\varepsilon_{r}$ is the real part of complex permittivity and $\mu_{r}$ the real part of complex permeability of the substrate [1]. Thus by increasing the real part of both $\varepsilon_{r}$ and $\mu_{r}$, the desired amount of miniaturization can be achieved. However, major shortfalls of using high $\varepsilon_{r}$ substrates are lowering of radiation efficiency, pattern degradation (due to excitation of surface waves) and lowering of impedance bandwidth [2, 3]. Miniaturization can also be achieved by increasing the other parameter $\mu_{r}$ (such as by using ferrite based materials). But, reports suggests that bulk ferrites generally have high saturation magnetization and dispersive magnetic losses [4-6] and needs strong external dc-bias fields to alter its permeability property [7], making it unsuitable for compact applications requiring higher efficiency. Further, shift of operational frequency of resonant devices on ferrite substrates due to application of external bias [8, 9] causes difficulty in integrating it with other systems. Lately, artificial magnetodielectric substrates are used to overcome issues of high loss in ferrites. Non-magnetic materials can be engineered with embedded circuits to achieve magnetic permeability [10]. However, the process of developing engineered artificial magnetic materials is complex [11-13].

On the other hand, composites made using nano ferrite inclusion in polymers can result in natural magnetodielectric materials with low magnetic losses. Also, $\varepsilon_{r}$ and $\mu_{r}$ of the composite can be altered by varying the amount of the inclusion to achieve the desired performance [14]. Moreover nano-sized ferrites are reported to have low saturation magnetizations and low eddy currentlosses as well[15, 16].

The current work reports the study of synthesis of such anelastic composite (Nickel substituted Cobalt ferrite in a Silicon Dioxide matrix mixed with silicone rubber) and its microwave characterization to determine its permittivity, permeability and its losses.

\section{EXPERIMENTAL WORK}

Synthesis of $\mathrm{x} \%\left(\mathrm{Co}_{0.65} \mathrm{Ni}_{0.35} \mathrm{Fe}_{2} \mathrm{O}_{4}\right) /(100-\mathrm{x}) \% \quad \mathrm{SiO}_{2} \quad(\mathrm{x}=$ $35 \%$ ) ferrimagnetic nanocompositeshave been carried out by an improvedmodified sol-gel method [17]. The sol-gel process offers some advantages in making silica composite materials containing highly dispersed nanoparticles; the process facilitates a good and homogeneous dispersion of 
the particles into the silica matrix [18]. The porous amorphous silica matrix provides, on one hand, nucleation centres for the nanoparticles and on the other hand reduces the aggregation phenomena, limiting the size of the formed oxide nanoparticles $[19,20]$.

A series with two basic ferrites were chosen to develop nanosized inclusions. $\mathrm{C}^{2+}$ ferrite offers low electrical conductivity and is also reported to have fast relaxing property due to its degenerate energy state [21]. However, $\mathrm{C}^{2+}$ ferrite is a hard magnet and it is difficult to change the spin orientation rapidly with variation in external magnetic field. Fast magnetic switching can be obtained by including $\mathrm{Ni}^{2+}$ stoichiometrically in cobalt ferrite. This switiching property is useful, if the resonant frequency of the microwave devices needs to be tuned at a later stage. $\mathrm{Ni}^{2+}$ ferrite is a soft ferrite and can be easily tuned with application of magnetic field [22]. In addition, $\mathrm{Ni}^{2+}$ ferrite has high Curie temperature ( 525 DC) making other magnetic properties independent of temperature. The stoichiometric ratio of $\mathrm{Co}$ and $\mathrm{Ni}$ considered in the current study, has been chosen from a previous study [23] conducted in the author's lab, which had exhibited the minimum value of magnetic losses in the frequency range of $8.2 \mathrm{GHz}$ to $12.4 \mathrm{GHz}$. Also, the value of $\mathrm{x}$ has been chosen to be $35 \%$, so as to avoid the phenomenon of agglomerization of the ferrite nano particles. [17]

In the synthesis process, TetraEthyl-OrthoSilicate (TEOS)(Merck, 98\%), metal nitrates (MN) (Merck (p.a.)): $\mathrm{Fe}\left(\mathrm{NO}_{3}\right)_{3} .9 \mathrm{H}_{2} \mathrm{O}, \quad \mathrm{Co}\left(\mathrm{NO}_{3}\right)_{2} .6 \mathrm{H}_{2} \mathrm{O}, \quad \mathrm{Ni}\left(\mathrm{NO}_{3}\right)_{2} .6 \mathrm{H}_{2} \mathrm{O}$, ethyleneglycol (EG), ethanol and $\mathrm{H}_{2} \mathrm{O}$ have been used.In the current study, two process routes have been followed. In one process, $\mathrm{H}_{2} \mathrm{O}$ have been added externally in the molar ratio of 1:7 with TEOS ( 1 part of TEOS with 7 parts of $\mathrm{H}_{2} 0$ ) [17] and in the other the process, no $\mathrm{H}_{2} \mathrm{O}$ was added externally. This was primarily carried out to study the effect of $\mathrm{H}_{2} \mathrm{O}$ in the process of ferrite formation through this modified sol-gel

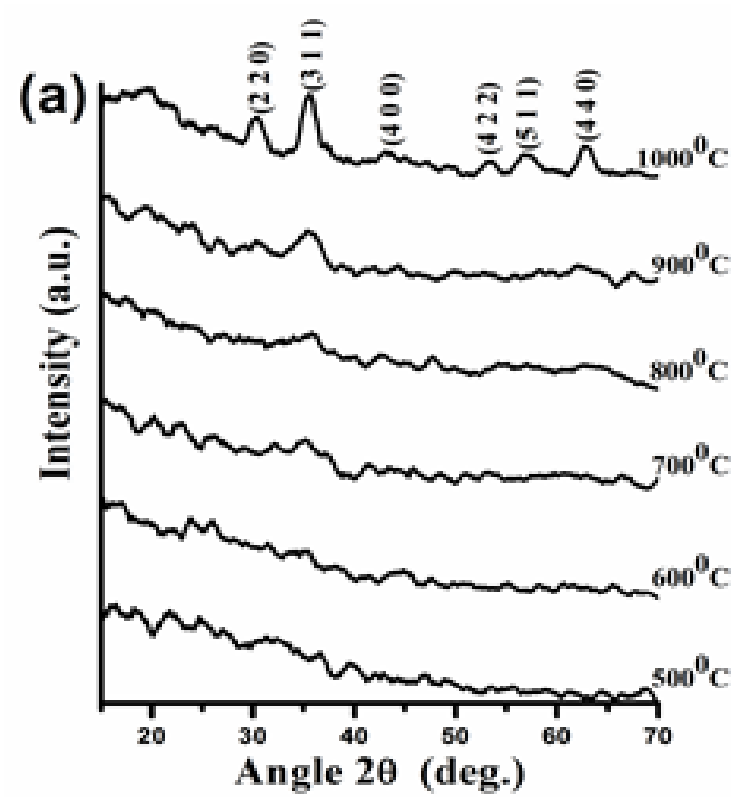

route [17] and its implication in the microwave properties of the composite.

Two solutions were prepared; in one solution tetraethylortosilicate (TEOS)-metal nitrates (MN)ethyleneglycol (EG) along with ethanol and externally added $\mathrm{H}_{2} \mathrm{O}$ were homogenously mixed in well determined composition [17], in order to obtain the desired $\mathrm{x} \%$ $\left(\mathrm{Co}_{0.65} \mathrm{Ni}_{0.35} \mathrm{Fe}_{2} \mathrm{O}_{4}\right) /(100-\mathrm{x}) \% \quad \mathrm{SiO}_{2}$ nanocomposites, where $\mathrm{x}$ $=35 \%$. The second solution was same, except that the solution was prepared without adding any amount of $\mathrm{H}_{2} \mathrm{O}$ externally. The two separate solutions were vigorously stirred and then left to gel at room temperature for around 72 hours.

The resultedgels were dried at $313 \mathrm{~K}$ for $3 \mathrm{~h}$, than grinded and heated at $403 \mathrm{~K}$. At this temperature the redox reaction ethyleneglycol-metal nitrates takes place with formation of thecorresponding carboxylate type precursor of ferrite nanoparticles [17].These precursors were decomposed by thermaltreatment at $573 \mathrm{~K}$ for $3 \mathrm{~h}$ in order to allow thereoxidation of $\mathrm{Fe}^{2+}$ to $\mathrm{Fe}^{3+}$ at low temperature. Theobtained powders were then separated into 6 batches and annealedfor $3 \mathrm{~h}$ at different temperatures $773 \mathrm{~K}, 873 \mathrm{~K}, 973 \mathrm{~K}, 1073 \mathrm{~K}$, $1173 \mathrm{~K}$ and $1273 \mathrm{~K}$ in order to obtain $\mathrm{x} \%$ $\left(\mathrm{Co}_{0.65} \mathrm{Ni}_{0.35} \mathrm{Fe}_{2} \mathrm{O}_{4}\right) /(100-\mathrm{x}) \% \mathrm{SiO}_{2}(\mathrm{x}=35 \%)$ nanocomposite.

The obtained nanocomposites were characterizedby X-ray diffraction (XRD), to determine the phase composition of the powders and to understand the effect of annealing temperature in the formation of ferrite. XRD was carried out using a Rigaku X-Ray Diffractometer, model: MINIFLEX using $\mathrm{Cu}-\mathrm{K} \square$ line of wavelength $\lambda=1.541841 \AA$. The average crystallite size was calculated based on the XRD patterns using the Scherrer's, DXRD $=0.9 \mathrm{k} / \mathrm{bcosh}$, where DXRD is the mean crystallite size, $\mathrm{k}$ is the radiation wavelength of $\mathrm{Cu}-\mathrm{K} \square(1.541841 \AA$ ), $\mathrm{b}$ is the full width at half of the maximum (FWHM) (in radians) and $\mathrm{h}$ is the Bragg angle.

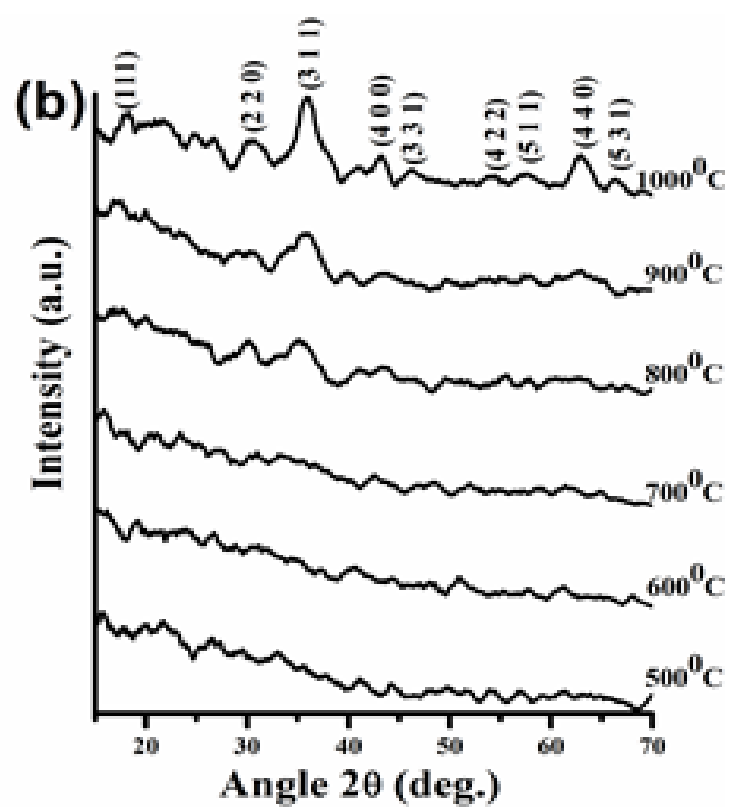

Fig 1: XRD of the nano composites annealed at different temperature prepared (a) with $\mathrm{H}_{2} \mathrm{O}$ (b) without $\mathrm{H}_{2} \mathrm{O}$ 
Fig. 1(a) is of the samples prepared by adding $\mathrm{H}_{2} \mathrm{O}$ externally and then obtained gels dried and annealed at different temperatures to form ferrites as shown in the figure. While Fig. 1(b) is of samples prepared without adding $\mathrm{H}_{2} \mathrm{O}$ externally. The figures quite clearly show the peak $(311)$ which is the ferrite peak, becomes prominent only at $1000{ }^{0} \mathrm{C}$ for both the cases, hence confirming the formation of ferrite phase. Considering the full width and half maxima of the $\left(\begin{array}{lll}3 & 1 & 1\end{array}\right)$ peak obtained at $1000{ }^{\circ} \mathrm{C}$, the crystalline size is found to be $7 \mathrm{~nm}$ for the one with $\mathrm{H}_{2} \mathrm{O}$ being added externally and $5 \mathrm{~nm}$ for the one without.

From the XRD graphs, it is seen that the ferrite phase peak prominence arises at around $1000{ }^{\circ} \mathrm{C}$, and therefore the powder samples that were annealed at $1000{ }^{0} \mathrm{C}$ were considered for moulding so as to attain a magnetodielectric substrate. For moulding and binding the powders, commercially available silicone rubber (Wacker, Germany) was used. Silicone rubber is very elastic, thus providing aflexible substrate structure. Flexible substrates can provide an advantage over rigid substrates in mounting over non planar bodies and conformal spaces. Silicone rubber can also handle temperatures as high as $250{ }^{\circ} \mathrm{C}$ and hence can prove to be a good candidate for microwave applications.

For moulding, the annealed powders (of both the cases i.e with $\mathrm{H}_{2} \mathrm{O}$ added and without $\mathrm{H}_{2} \mathrm{O}$ being added) were mixed in 1:1 ratio by weight with silicone rubber and mixed vigorously. The mixture was then poured into a mould of fixed dimension $(22.86 \times 10.16 \mathrm{~mm})$, which is the standard dimension required for complex permittivity and complex permeability measurements in the frequency range of 8.2 $\mathrm{GHz}$ to $12.4 \mathrm{GHz}$ (also known as X-band). The thicknesses of the samples werearbitrarily kept as $4 \mathrm{~mm}$, as the complex permittivity and complex permeability does not depend on the thickness of the sample. The mixture was then kept in the mould for around 48 hours to be allowed to get cured. The obtained samples were very flexible in nature as shown in the figure below.

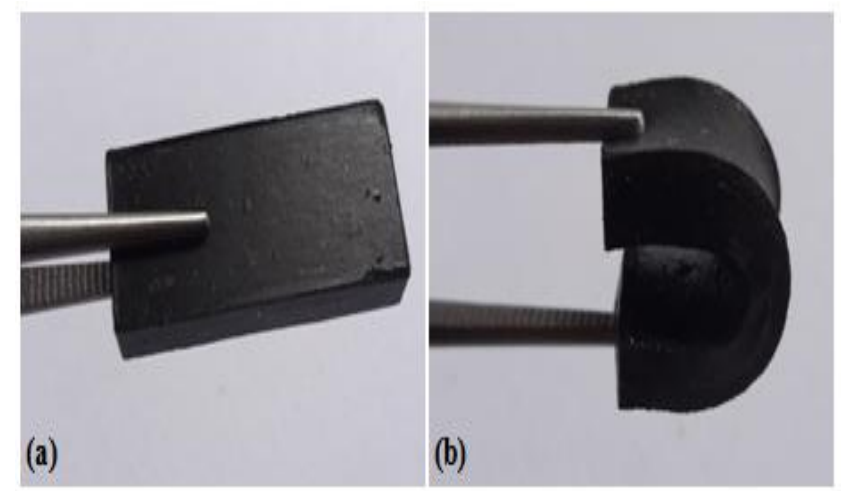

Fig 2: Developed magnetodielectric flexible substrate for the sample with $\mathrm{H}_{2} \mathrm{O}$ in (a) relaxed and (b) bended position

Complex permittivity and complex permeability of the two samples over the X-band (8.2-12.4 GHz)weremeasured using the transmission/reflection method, using Agilent WR-90 11644A rectangular waveguide line compatible with Agilent E8362C vector network analyzer [24]. The graphs below show the obtained results.
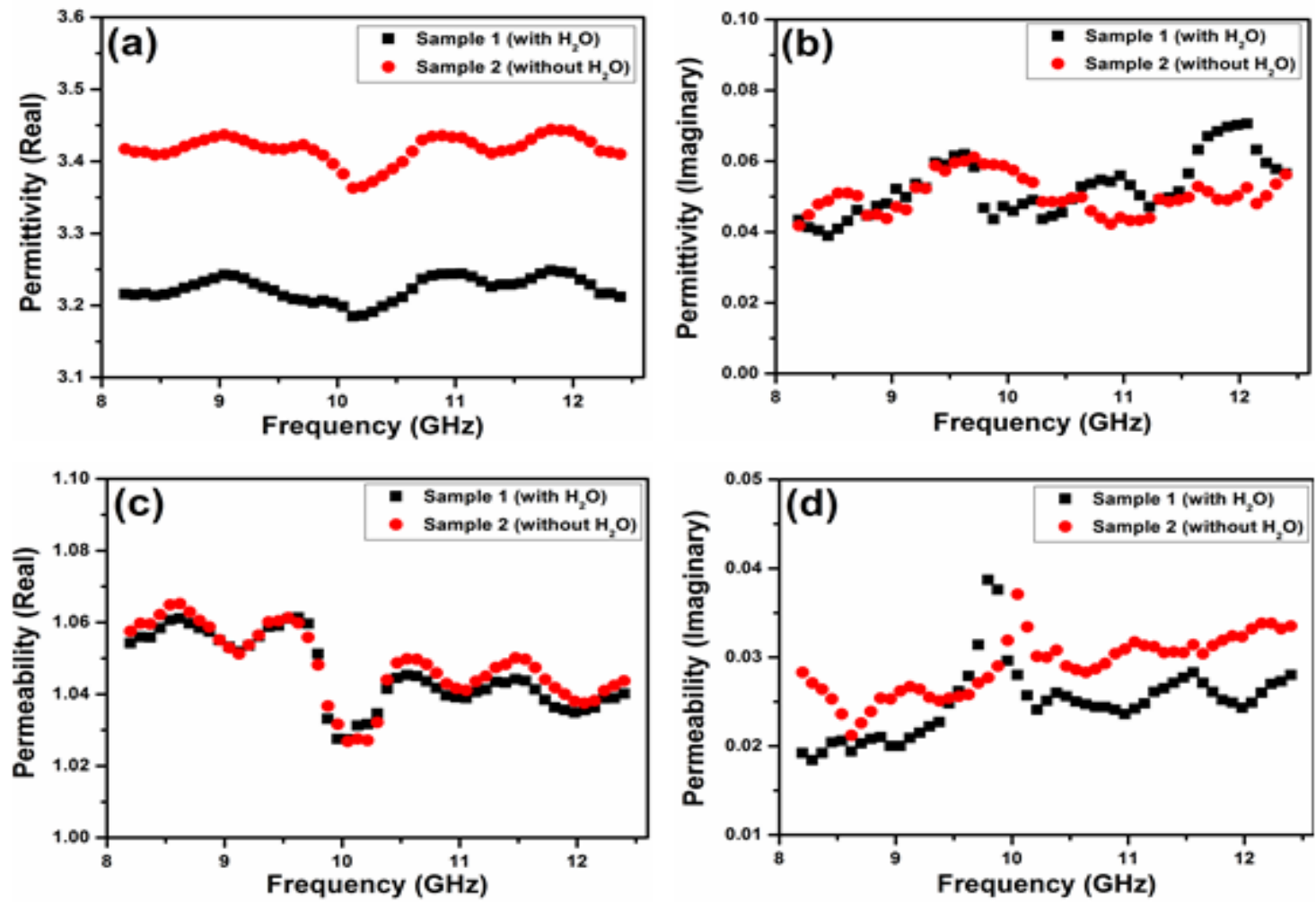

Fig 3: (a) Real part of permittivity of both samples (b) Imaginary part of permittivity of both samples (c) Real part of permeability of both samples (d) Imaginary part of permeability of both samples. 


\section{DISCUSSIONS}

From the evolution of the diffraction peaks, it is obvious that the degree of crystallization increases with annealing temperature, with the peaks appearing from about $800{ }^{\circ} \mathrm{C}$ for both the cases. The small value of the crystalline size $(5 \mathrm{~nm}$ and $7 \mathrm{~nm}$ ) may be attributed to the fact that the pores of the $\mathrm{SiO} 2$ matrix limit the ability of the ferrite nano particles to increase their size. Also the plot for the sample prepared using $\mathrm{H}_{2} \mathrm{O}$ showed lesser number of peaks as compared to the sample prepared without $\mathrm{H}_{2} \mathrm{O}$. This indicates that the number of secondary phases formed in the former case is higher than that of the latter. The $\left(\begin{array}{lll}1 & 1 & 1\end{array}\right)$ peak present in the case of the samples prepared without $\mathrm{H}_{2} \mathrm{O}$, signify the presence of the $\mathrm{Fe}_{2} \mathrm{SiO}_{4}$ phase, which is undesirable and may lead to unwanted losses in the final substrate. This peak is however not present in the case of the samples prepared with $\mathrm{H} 2 \mathrm{O}$ and hence this process may be considered as the favourable process in the current scenario.

Considering the permittivity curves, the real part of the samples prepared with $\mathrm{H}_{2} \mathrm{O}$ (sample 1) show lower values than that of the one without (sample 2). The imaginary part of the permittivity which represent dielectric losses, do not provide us with a conclusive picture, although within the mid frequency ranges sample 2 show higher losses, towards the higher frequencies sample 1 show higher losses.

However, the imaginary part of the permeability curves clearly illustrate, that the sample 2 (i.e. without $\mathrm{H}_{2} \mathrm{O}$ ) have higher magnetic losses as compared to sample 1 (i.e. with $\mathrm{H}_{2} \mathrm{O}$ ). Butler et al[25], showed that with lower value of water content, a matrix with amore open structure is produced due toincomplete hydrolysis and, consequently,less cross linking in the sol-gel material. A low water content or high dilution with alcohols (solvents) can lead to a high content of oligomers (soluble or volatile) and adecrease in the yield of $\mathrm{SiO}_{2}$. The presence of partially hydrolysed monomers and those different types of oligomers can affect the composition and the homogeneity of the final material $[26,27]$. This effect in the homogeneity may be the cause for the observed inconsistency in the magnetic losses exhibited by the samples.

\section{CONCLUSION}

The paper presents a modified sol gel route to synthesize $\mathrm{x} \%$ $\left(\mathrm{Co}_{0.65} \mathrm{Ni}_{0.35} \mathrm{Fe}_{2} \mathrm{O}_{4}\right) /(100-\mathrm{x}) \% \quad \mathrm{SiO}_{2} \quad(\mathrm{x}=35 \%)$ nanocomposites. The synthesized nanocomposite powders were mixed with silicone rubber to obtain a flexible structure. The obtained substrates were characterized for their permittivity and permeability. The real part of permittivity showed values around 3.2-3.4 and permeability values above 1, which indicate that the substrate is magnetodielectric in nature. This can lead to a certain degree of miniaturization, although it has some further scope of improvement. Also the imaginary part of permittivity and permeability which exemplify the dielectric and magnetic loss of the substrate respectively were found to be well below 1 , and hence the substrates synthesized can be termed to be low loss substrates.
Moreover, the XRD curves and the magnetic losses signifies that the nano composite sample prepared by adding $\mathrm{H}_{2} \mathrm{O}$ externally and mixed with silicone rubber is more favourable to be considered as a low loss magnetodielectric substrate in the frequency range of 8.2 to $12.4 \mathrm{GHz}$ (Xband).

\section{REFERENCES}

[1] Petrov, R. V., Tatarenko, A. S., Srinivasan, G., \& Mantese, J. V. (2008). Antenna miniaturization with ferrite ferroelectric composites. Microwave and Optical Technology Letters, 50(12), 3154-3157.

[2] Wheeler, H. A. (1947). Fundamental limitations of small antennas.Proceedings of the IRE, 35(12), 14791484.

[3] Fujimoto, K., Henderson, A., Hirasawa, K., \& James, J. R. (1987). Small antennas (pp. 236-238). Baldok, Hertfordshire: Research Studies Press.

[4] Luo, H. Y., Yue, Z. X., \& Zhou, J. (2000). Synthesis and high-frequency magnetic properties of sol-gel derived Ni-Zn ferrite-forsterite composites.Journal of magnetism and magnetic materials, 210(1), 104-108.

[5] Nejati, K., \& Zabihi, R. (2012). Preparation and magnetic properties of nano size nickel ferrite particles using hydrothermal method. Chemistry Central Journal, 6(1), 1.

[6] Singh, S., Ralhan, N. K., Kotnala, R. K., \& Verma, K. C. (2012). Nanosize dependent electrical and magnetic properties of $\mathrm{NiFe} 2 \mathrm{O} 4$ ferrite. Indian Journal of Pure and Applied Physics, 50(10), 739743.

[7] Vollinger, C., Caspers, F., \& Jensen, E. (2013). The effect of 2-directional magnetic biasing used for tuning of a ferrite-loaded re-entrant cavity. IEEE Transactions on Nuclear Science, 60(3), 2170-2174.

[8] Saxena, N. K., \& Pourush, P. K. S. (2008, November). Microstrip array antenna on biased ferrite substrate as signal to noise enhancer. In Recent Advances in Microwave Theory and Applications, 2008. MICROWAVE 2008. International Conference on (pp. 896-897). IEEE.

[9] Yang, G. M., Xing, X., Obi, O., Daigle, A., Liu, M., Stoute, S., ... \& Sun, N. X. (2010). Loading effects of self-biased magnetic films on patch antennas with substrate/superstrate sandwich structure. IET microwaves, antennas \& propagation, 4(9), 11721181.

[10] Kostin, M. V., \& Shevchenko, V. V. (1994). Artificial magnetics based on double circular elements, in: Proc. of Bianisotropics' 94. Perigueux, France, 49.

[11] Kärkkäinen, M., \& Ikonen, P. (2005). Patch antenna with stacked split-ring resonators as an artificial magneto-dielectric substrate. Microwave and Optical Technology Letters, 46(6), 554-556.

[12] Buell, K., Mosallaei, H., \& Sarabandi, K. (2006). A substrate for small patch antennas providing tunable miniaturization factors. IEEE Transactions on Microwave Theory and Techniques, 54(1), 135-146. 
[13] Ikonen, P. M., Maslovski, S. I., Simovski, C. R., \& Tretyakov, S. A. (2006). On artificial magnetodielectric loading for improving the impedance bandwidth properties of microstrip antennas. IEEE transactions on antennas and propagation, 54(6), 1654-1662.

[14] Mazaleyrat, F., \& Varga, L. K. (2000). Ferromagnetic nanocomposites.Journal of Magnetism and Magnetic Materials, 215, 253-259.

[15] Uskoković, V., Drofenik, M., \& Ban, I. (2004). The characterization of nanosized nickel-zinc ferrites synthesized within reverse micelles of $\mathrm{CTAB} / 1-$ hexanol/water microemulsion. Journal of magnetism and magnetic materials, 284, 294-302.

[16] Son, S., Taheri, M., Carpenter, E., Harris, V. G., \& McHenry, M. E. (2002). Synthesis of ferrite and nickel ferrite nanoparticles using radio-frequency thermal plasma torch. Journal of Applied Physics, 91(10), 7589-7591.

[17] Stoia, M., Caizer, C., Ştefănescu, M., Barvinschi, P., \& Barbu-Tudoran, L. (2011). Characterisation of nickel-zinc ferrite/silica nanocomposites with low ferrite concentration obtained by an improved modified sol-gel method.Journal of sol-gel science and technology, 58(1), 126-134.

[18] Gharagozlou, M. (2010). Study on the influence of annealing temperature and ferrite content on the structural and magnetic properties of $\mathrm{x}$ $\left(\mathrm{NiFe}_{2} \mathrm{O}_{4}\right) /(100-\mathrm{x}) \mathrm{SiO}_{2}$ nanocomposites. Journal of Alloys and Compounds,495(1), 217-223.

[19] Manova, E., Tsoncheva, T., Paneva, D., Rehspringer, J. L., Tenchev, K., Mitov, I., \& Petrov, L. (2007). Synthesis, characterization and catalytic properties of nanodimensional nickel ferrite/silica composites. Applied Catalysis A: General, 317(1), 34-42.

[20] Chatterjee, A., Das, D., Chakravorty, D., \& Choudhury, K. (1990). Mössbauer spectra of nanocrystalline $\mathrm{Fe}$ and $\mathrm{Fe}-\mathrm{Cr}$ particles in sol-gel-derived SiO2 glass. Applied Physics Letters, 57(13), 1360-1362.

[21] OBryan, H. M., GALLAGHE. PK, Monforte, F. R., \& Schrey, F. (1969). Microstructure Control in Nickel Ferrous Ferrite. AMERICAN CERAMIC SOCIETY BULLETIN, 48(2), 203.

[22] Gao, B., Qiao, L., Wang, J., Liu, Q., Li, F., Feng, J., \& Xue, D. (2008). Microwave absorption properties of the Ni nanowires composite. Journal of Physics D: Applied Physics, 41(23), 235005.

[23] Borah, S. (2011). Study of microstrip transmission line and adaptable radial stub resonator on nickel substituted cobalt ferrite/LDPE nanocomposite as magneto-dielectric substrate at X-band (Doctoral dissertation).

[24] Baker-Jarvis, J. (1990). Transmission/reflection and short-circuit line permittivity measurements. Colorado: National Institute of Standards and Technology.

[25] Butler, T. M., MacCraith, B. D., \& McDonagh, C. (1998). Leaching in sol-gel-derived silica films for optical pH sensing. Journal of Non-Crystalline Solids, 224(3), 249-258.

[26] Schmidt, H. K., Geiter, E., Mennig, M., Krug, H., Becker, C., \& Winkler, R. P. (1998). The sol-gel process for nano-technologies: new nanocomposites with interesting optical and mechanical properties. Journal of sol-gel science and technology, 13(1-3), 397-404.

[27] Milea, C. A., Bogatu, C., \& Duta, A. (2011). The influence of parameters in silica sol-gel process. Bulletin of TheTransilvania University of Brasov, 4, 53. 